\title{
Correction to: Affine connections on 3-Sasakian homogeneous manifolds
}

\author{
Cristina Draper $^{1}$ (D) $\cdot$ Miguel Ortega ${ }^{2}$ (D) Francisco J. Palomo ${ }^{1}$ (D)
}

Published online: 27 July 2019

(c) Springer-Verlag GmbH Germany, part of Springer Nature 2019

\section{Correction to: Mathematische Zeitschrift https://doi.org/10.1007/s00209-019-02304-x}

In the original publication of this article, the title was incorrectly published as "Affine connections on 3-Sasakian and manifolds". The correct title should be "Affine connections on 3-Sasakian homogeneous manifolds".

Publisher's Note Springer Nature remains neutral with regard to jurisdictional claims in published maps and institutional affiliations.

The original article can be found online at https://doi.org/10.1007/s00209-019-02304-X.

$凶 \quad$ Miguel Ortega

miortega@ugr.es

Cristina Draper

cdf@uma.es

Francisco J. Palomo

fjpalomo@ctima.uma.es

1 Departamento de Matemática Aplicada, Escuela de Ingenierías Industriales, Universidad de Málaga, 29071 Málaga, Spain

2 Departamento de Geometría y Topología, Facultad de Ciencias, Instituto de Matemáticas IEMathUGR, Universidad de Granada, 18071 Granada, Spain 